\title{
Identification of Tick and Tick Borne Hemo-Parasites in Tiyo District, Arsi Zone, Oromia Region
}

\author{
Tolosa Shane ${ }^{1}$, Teshome Gunse ${ }^{1}$ and Fanos Tadesse Woldemariyam ${ }^{2 *}$ \\ ${ }^{1}$ Arsi Zone Livestock and Fisheries Development Office, Ethiopia \\ ${ }^{2}$ College Veterinary Medicine and Agriculture, Addis Ababa University, Ethiopia
}

\begin{abstract}
This study was conducted between November 2014 to march 2015 in Tiyo district and the surrounding peasant associations to determine the prevalence of tick and tick- born haemo-parasites in local and exotic cattle. A total of 384 local, exotic and cross breed cattles of all age group and sex group were included in this study. Four genera of ticks namely Amblyoma, Boophilus, Rhepicephalus and Hyaloma were identified with prevalence rate of $(72 \%, 15 \%$, $3 \%, 6.5 \%)$ respectively. From these ticks Boophilus constituted a high percentage of prevalence $(72 \%)$ followed by Amblyoma(15\%), Rhepicephalus $(6.5 \%)$ and Hyaloma (3\%) respectively. Out of 371 animals which were infested with ticks thin blood smears were examined for tick-borne protozoan parasites. From this 8 out of 371 were positive and 6 animals were found to be positive for Babesiosis while 2 of them for Anaplasmosis with prevalence rate of $1.6 \%$ and $0.5 \%$ respectively. Although it is difficult to deduct conclusive ideas about the general incidence and prevalence of hemo-parasites due to the short interval of the survey period, especially which did not include the wet season, it is clear that tick and tick borne haemoparasites constitutes a very important place in the area.
\end{abstract}

Keywords: Cattle; Haemo-parasite; Tick-born; Tiyo district; Tick species

\section{Introduction}

Ethiopia a country located in the horn of Africa has an extremely diverse topography which is suitable for different agricultural production (crop, livestock). The livestock population of Ethiopia is estimated to be about 50 million cattle, 23 million sheep, 18 million goats, 1.65 million equines and 42 million poultry representing $45 \%$ of agricultural output/GDP in Ethiopia. Export commodities (meat, live animals, hides and skins as well as drought power, milk production and as source of manure are the main outputs of livestocks $[1,2]$.

Ticks effects on animals include loss of blood (anemia), Tick toxicosis, tick worry bite wound, wounds and myiasis, tick-borne diseases $[3,4]$. Studies conducted on the ticks and tick-borne diseases of cattle in Ethiopia showed several species of ticks belonging to genus Amblyomma, Boophilus, Rhipicephalus, Hyalomma and Haemaphysalis [5].

It has been estimated that about $80 \%$ of the world population of cattles are infested with ticks [6]. Tick and tick borne diseases causes a tremendous economic importance in livestock production in tropical and subtropical countries [7]. From animal health and economic point of view tick borne disease of ruminants are certainly the most important [8] but no realistic prospects for the eradication of tick and tick-borne diseases has been developed elsewhere in the world [9].

These economically most important haemo-parasitic tick borne diseases of ruminant on a global scale are Babesiosis, Anaplasmosis, Theileriosis and Cowdriosis of cattle and small ruminants [10]. According to FAO (1984) global estimation on tick and tick-borne diseases and with the assumption of $80 \%$ infestation of world 1226 million cattle were infested by ticks with estimated to annual loss from each animal to be of US\$ 7.36. Accordingly, Ethiopia with 50 million cattle population may suffer an annual loss of US \$ 368 million only from large ruminants [11].

In Ethiopia, various surveys showed the abundance of tick species on livestock in different regions of the country. More than 60 species of ticks have been recorded infesting both domestic and wild animals among which about 33 species are widespread and are important parasite of livestock [12-16]. However, the statuses of ticks and tickborne hemo-parasites are not thoroughly studied in Tiyo District of Arsi Zone and information are so far scanty. Some reports from the veterinary clinics reveal the existence of ticks and haemo-parasites using routine parasitological examination technique.

There for, the objectives of this study were to:

- Determine the prevalence of tick-borne haemo-parasites in cattle coming to Tiyo District Veterinary clinic and fattening farms in and around Assela.

- Identify the major tick species infesting cattle coming to Tiyo District Veterinary clinic and fattening farms.

\section{Materials and Methods}

\section{Study area}

Arsi Zone is in Oromia region. It is located in south east of Ethiopia within $6^{\circ} 59^{\prime}$ and $8^{\circ} 49^{\prime} \mathrm{N}$ latitude and $38^{\circ} 41^{\prime}$ and $40^{\circ} 44^{\prime} \mathrm{E}$ longitude. Tiyo dstrict, is located $175 \mathrm{~km}$ south east of Addis Ababa and It comprises of Assela town and Villages around it. The altitude of the district ranges from 1650-3000 meters above sea level (Masl). About $37 \%$ of the total area is highland (>2400 m); $52 \%$ mid-land $(1800-2400$ m) $11 \%$ is low-land $(<1800 \mathrm{~m})$ (Central planning Authority, 1994). The area has daily maximum temperature that reaches up to $28^{\circ} \mathrm{C}$ and

${ }^{*}$ Corresponding author: Woldemariyam FT, College Veterinary Medicine and Agriculture, Addis Ababa University, Ethiopia, Tel: +251911242551; E-mail: fanos.tadesse@aau.edu.et

Received January 24, 2017; Accepted January 30, 2017; Published January 31, 2017

Citation: Shane T, Gunse T, Woldemariyam FT (2017) Identification of Tick and Tick Borne Hemo-Parasites in Tiyo District, Arsi Zone, Oromia Region. J Vet Sci Technol 8: 418. doi: 10.4172/2157-7579.1000418

Copyright: (c) 2017 Shane T, et al. This is an open-access article distributed under the terms of the Creative Commons Attribution License, which permits unrestricted use, distribution, and reproduction in any medium, provided the original author and source are credited. 
minimum temperature of $10^{\circ} \mathrm{C}$ with an annual rainfall that ranges from $700-1658 \mathrm{~mm}$ and annual average relative humidity, ranging from 43$60 \%$. The area has a bimodal rainfall occurring form March to April (a short rainy season) and from July to October (long rainy season). The common and widely used livestock production system in the area is an extensive type of production system where animals are kept only on grazing with no extra supplementary feed except crop residues during dry season. But there are few indoor, intensive animal production systems particularly in Assela town.

\section{Study design}

A cross-sectional study was designed to address the objective of this investigation. Both district veterinary clinics and Animal health posts as well as small scale farms were selected for the study. Simple random sampling was used for both infected and non infected animals irrespective of their age, breed, sex, and agro-ecology to collect ticks and blood sample.

\section{Study animal}

For this study the sample size from Assela and the surrounding area is determined for definite precision and level of confidence. A 95\% $\mathrm{CI}$ and $5 \%$ with $50 \%$ expected prevalence was used in determining the sample size.

$$
\begin{aligned}
& \text { i.e., } N=\frac{\left.1.96^{2} P \exp (1-) \exp \right)}{d^{2}} \\
& \frac{\left.1.96^{2} 0.5(1-05) \exp \right)}{0.05^{2}}
\end{aligned}
$$

For this study a total of 384 animals were sampled to collect tick and blood.

\section{Sampling and sample processing}

Ticks were collected gently from half body regions of the selected cattle and their species were identified and thin blood smears were taken from the ear vein of cattle coming to Tiyo district veterinary clinic, Veterinary health posts found in the district and farms. History of all cattles were recorded. This samples were brought to Assela regional laboratory and were processed as follows.

Collection and examination of blood sample: Thin blood smears were taken from one of the small blood vessels of the ear making sure to take the first drop so as to not miss the parasites. The blood smears stained with $10 \%$ Geimsa solution and the haemo-parasites were looked for in the red blood cells of the smear under the oil immersion objective of the microscope.

Collection and identification of ticks: Ticks which were collected from the animals and preserved in $10 \%$ formalin solution and identified under stereomicroscope using key morphological characteristics as describd by Urquhart et al. and Soulsby $[17,18]$.

\section{Data Analysis}

Descriptive data analysis was employed in summarizing the data regarding haemo-parasitic disease and major tick isolated in cattle of different sex, breed, altitude and group of animal. Chi-square test of independence was employed in comparing the prevalence of haemoparasitic diseases with respect to altitude; sex and age as well as breed to determine the association of risk factors and occurrence of haemopasitic disease in cattle.

\section{Results}

Out of 384 cattle examined (Cross $n=41$, Exotic $n=6$, Local $n=337$ ) $371(96.5 \%)$ were found to be infected with different genera of ticks. Four general of ticks namely; Boophilus (72\%), Amblyomma (15\%), Rhipicephalus (6.5\%) and Hyalomma (3\%) were identified (Table 1). Similarly from 384 blood samples collected thin blood smears were stained and examined for the presence of haemo-parasites out of which, $8(2.1 \%)$ were found to be infected with different haemo-parasites (Table $4)$.

Boophilus takes the largest share in infesting all the three Agroecology of cattles with more than $70 \%$ prevalence which is followed by Aambylyoma species except the midland having 66\% (Table 3). With respect to breed, sex and age tick infestation it was Boophilus tick species which took the largest share except the youner cattles were found to be infested with Amblyomma species (Table 2).

From the total of 384 cattles examined 371 animals were found to be infested with ticks from this cattles blood sample (smear) were collected and examined for the presence of haemo-parasites. Of which $8(2.1 \%)$ prevalence was found to be positive for hemo-parasite. From this it was found that 6 out of 371(1.61\%) were positive for Babesia and $2(0.53 \%)$ were found to be positive for Anaplasmosis (Table 4).

\section{Discussion}

In this study period (November 2014 to March 2015) a total of 384 cattle were examined and found four genera of ticks in 371(96\%) cattles. These 371 heads of cattles were again subjected to thin smear preparation and examined for the presence of hemo-parasites. In this regard $8(2.1 \%)$ of blood smears were found to be haemo-parasite. Two haemo-paraites namely, Babesia (1.6\%) and Anaplasma(0.5\%) were identified during the study.

Boophilus was the dominate tick identified followed by Amblyomma, Rhipicephalus and Hyalomma respectively. This findings disagree in figure but agrees with the genera identified with Mekonen and partially agreed with Belew and Mekonin who reported that the major tick genera recorded in tick distribution survey, made in Ethiopia were Amblyomma (40\%), Rhipicephalus (37\%), Boophilus(21\%) and Hyalomma (1.5\%). This could be due to difference in the season during which the study was conducted $[19,20]$. Even though the percentage between Amblyomma and Boophilus differs it is common to find the four genera of ticks which were prevalent in Ethiopia. Pawlos Wasihun and Derese Doda, were also stated that three out of four of our tick genera were prevalent in Ethiopia [21]. But our finding was in agreement with the explanation that Boophilus tick is present in areas with long rainy season which is true for Tiyo district [22]. This was also in agreement with the findings of Sinshaw at Metekel ranch which found tick in wet season [23].

\begin{tabular}{|c|c|c|c|}
\hline \multirow{2}{*}{ Ticks species } & \multicolumn{2}{|c|}{ Agro-ecology } \\
\cline { 2 - 4 } & Highland $(\mathrm{n}=178)$ & Mid land $(\mathrm{n}=50)$ & \\
\hline Rhipicephalus & $8(4.6 \%)$ & $3(6 \%)$ & $14(9 \%)$ \\
\hline Amblyomma & $25(14 \%)$ & $3(18 \%)$ & $24(16 \%)$ \\
\hline Boophilus & $133(74.7 \%)$ & $3(66 \%)$ & $110(70.5 \%)$ \\
\hline Hayalomma & $7(4 \%)$ & $2(4.2 \%)$ & $3(2 \%)$ \\
\hline
\end{tabular}

Table 1: Over all prevalence of ticks species identified in Tiyo district, Arsi Zone. 


\begin{tabular}{|c|c|c|c|c|c|c|c|}
\hline \multirow{2}{*}{ Ticks species } & \multicolumn{3}{|c|}{ Breed } & \multicolumn{2}{|c|}{ Sex } & \multicolumn{2}{|c|}{ Age } \\
\hline & Cross $n=41$ & Exotic $n=6$ & Local $n=337$ & Female $n=75$ & Male $n=300$ & Adult $n=363$ & Young $n=21$ \\
\hline Rhipicephalus & $3(7.3 \%)$ & 0 & $22(6.5 \%)$ & $3(4 \%)$ & $22(7.3 \%)$ & $22(6.1 \%)$ & $3(14.3 \%)$ \\
\hline Amblyomma & $6(14 \%)$ & $1(17 \%)$ & $51(15 \%)$ & $25(33 \%)$ & $33(11 \%)$ & $40(11 \%)$ & $18(85.7 \%)$ \\
\hline Boophilus & $30(73.2 \%)$ & $5(83 \%)$ & $241(71.5 \%)$ & $53(70.7 \%)$ & $223(74.3 \%)$ & $260(71.6 \%)$ & $16(76.2 \%)$ \\
\hline Hayalomma & $2(4.9 \%)$ & 0 & $10(3 \%)$ & $3(4 \%)$ & $9(3 \%)$ & $11(3.03 \%)$ & $1(4.8 \%)$ \\
\hline
\end{tabular}

Table 2: The prevalence of ticks among, breed, sex and age group of cattle.

\begin{tabular}{|c|c|c|c|}
\hline \multirow{2}{*}{ Ticks species } & \multicolumn{3}{|c|}{ Agro-ecology } \\
\cline { 2 - 4 } & Highland $(\mathrm{n}=178)$ & Mid land $(\mathrm{n}=50)$ & $3(6 \%)$ \\
\hline Rhipicephalus & $8(4.6 \%)$ & $9(18 \%)$ & $14(9 \%)$ \\
\hline Amblyomma & $25(14 \%)$ & $33(66 \%)$ & $24(16 \%)$ \\
\hline Boophilus & $133(74.7 \%)$ & $2(4.2 \%)$ & $110(70.5 \%)$ \\
\hline Hayalomma & $7(4 \%)$ & $3(2 \%)$ \\
\hline
\end{tabular}

Table 3: The prevalence of ticks among agro-ecology of Tiyo District.

\begin{tabular}{|c|c|c|c|c|c|c|c|c|c|c|}
\hline \multirow{2}{*}{$\begin{array}{l}\text { Haemo- } \\
\text { parasite }\end{array}$} & \multicolumn{3}{|c|}{ Agro-ecology } & \multicolumn{3}{|c|}{ Breed } & \multicolumn{2}{|c|}{ Sex } & \multicolumn{2}{|c|}{ Age } \\
\hline & High land $t n=178$ & Mid land $n=50$ & Low land $n=156$ & Cross $n=41$ & Exotic $n=6$ & Local $n=337$ & Female $n=75$ & Male $n=300$ & Adult $n=363$ & Young $n=21$ \\
\hline Babesia & $4(2.2 \%)$ & 0 & $2(1.3 \%)$ & $1(2.4 \%)$ & 0 & $5(1.5 \%)$ & $3(4 \%)$ & $3(1 \%)$ & $5(1.4 \%)$ & $1(4.8 \%)$ \\
\hline Anaplasma & 0 & 0 & $2(1.5)$ & 0 & 0 & $2(0.6)$ & 0 & $2(0.6 \%)$ & $2(0.6 \%)$ & 0 \\
\hline
\end{tabular}

Table 4: The prevalence of haemo-parasites among agro-ecology, breed, sex and age.

Rhipicephalus is the $3^{\text {rd }}$ and Hyalomma is the $4^{\text {th }}$ encountered tick genera in the area. Rhipicephalus is the most common tick genera in the study area during the period covered. It was more identified in the low land and followed by high land and midland. It was highly dominate in the low land areas in Dera around $50 \mathrm{~km}$ distance form Assela town. In general; Boophilus, Amblyomma and Rhipicephalus ticks constitutes highest percentage of the total collection. The Hyalomma and other tick species were found in limited number or not found in our study site this is in agreement with the finding of Mekonin et al. [19]. In the present study only 8 positive cases were observed for hemo-parasite, of which six animals were positive for Babesia parasite and the other two were positive for Anaplasma parasite.

Infection by $A$. marginale is wide spread in the country as its major tick vector is $B$. decoloratus [24]. Babesiosis is mainly a disease of cattle in Ethiopia and is caused by Babesia bigemina whose vector is $B$. decoloratus and Babesia bovis whose vector is B. annualtus.

Our finding was in agreement with a report of Mekonnen, which states that Clinical cases of Babesiosis are encountered rarely [19]. Additionally rare prevalence of tick born diseases this could be due to the fact that thin blood smear examination and other simple laboratory procedures were not very efficient procedures were not very efficient means of identifying tick-borne haemoparasites [7]. Anaplasmosis, Babesiosis, Cowdriosis and theileriosis together with a range of vector tick species are found in Ethiopia [24].

A 1992 serological survey of tick-borne diseases in private and state dairy farms with their cross -breed cattle reported high percentage of antibodies against $A$. marginal (>90\%). Babesia begemina (60\%) and $T$. mutans $(30 \%)$ indicating a fair level of enzootix stability in respect to those tick-borne diseases each tick-borne haemo-parasites may have a restricted number of tick species which acts as effective vector [19].

\section{Conclusion and Recommendations}

Ticks and the disease they cause and transmit are among the important livestock problem. They are the main causes of decreased productivity and they expose animals to a number of diseases out breaks in the area. Although it is difficult to deduct conclusive ideas about the general incidence and prevalence due to the short interval of the survey period, especially which did not include the wet season, it is clear that tick borne haemo-parasites constitutes a very important place in the area. Taking into account the demand for livestock in the region and that the ticks are the main problems in upgrading animals productivity of ticks and tick borne diseases are among remarkable problems in the study area.

Based on the above conclusive remarks, the following recommendations are given:

$>$ Detailed epidemiological studies should be conducted on ticks and tick born disease in different season's indifferent species of domestic animals.

$>$ Country wide effective tick and tick-born disease control strategies should be designed

$>$ Efforts to be made to introduce community based tick controlling strategies

$>$ Veterinary professionals mainly technicians should be trained on the effective and modern field diagnostic techniques of tick borne diseases.

\section{References}

1. Kidane C (2001) Hides and skins defects, nature and effects on the industry technical work shop on good practices for the Ethiopian hides and skins industry. Addis Ababa, Ethiopia, December 4-7, 2001. p: 8.

2. Solomon G (2005) Agriculture in Ethiopia: ICIPE tick modeling work shop held at Duduviell Report on 9-19 October 1997. Nairobi, Kenya.

3. Daniel ES, Robert SL, William LN (2012) Medical and Veterinary Entomology. Elsevier Science, USA, pp: 517-558.

4. Bowman DD (2009) Class Arachnida: Georgis' Parasitology for Veterinarians 9th edn. Saunders Elsevier, USA, pp: 40-60.

5. Nibret MB, Basaznew B, Tewodros F (2012) Hard Ticks (Ixodidae): Species Composition, Seasonal Dynamics and Body Site Distribution on Cattle in Chilga District, Northwest Ethiopia. Asian J Agric Sci. 4: 341-345.

6. Minjauw B, McLeod A (2003) Tick borne diseases and poverty. The impact of ticks and tick borne diseases on livestock owners in India and Eastern health program center for tropical veterinary medicine. University of Edinburgh, UK, pp: 24-57. 
Citation: Shane T, Gunse T, Woldemariyam FT (2017) Identification of Tick and Tick Borne Hemo-Parasites in Tiyo District, Arsi Zone, Oromia Region. J Vet Sci Technol 8: 418. doi: 10.4172/2157-7579.1000418

7. FAO (1984) Ticks and tick born diseases control. A practical field manual. Vol 1. I FAO, Rome, pp: 1-30.

8. Kocan KM (1995) Targeting tick for control of selected haemopatasite disease cattle. Veterinary Parasitology 57: 121-151.

9. Eshetu Y (1986) Prevalence of tick born hemo-parasitie in Bahirdar Awraja. DVM Thesis. FVM, AAU, Debre zeit, Ethiopia.

10. Uilenberg $G$ (1995) International collaborative research significance of tick borne. Vet Parasitol 57: 19-41.

11. FAO (1991) Tick and tick born diseases control. A particular field manual Vol. II. Tick Born disease control. FAO, Rome, pp: 301-362.

12. Morel PC (1980) Study of Ethiopia ticks. Acarina, ixodidael. Ministry of Foreign Affairs, IEMCT, France.

13. Pegram RE (1981) Tick (Ixodoidea) of Ethiopia with special reference to cattle and a critical review of the taxonomic status of species within the and Rhipicephalus sanguineus gros. M Phil Thesis, Burnel University, Uxbridge, England, UK.

14. Feseha $F(1983)$ Notes on tick species and tick born diseases of domestic animals. In: Ethiopia, FVM, AAU, Debre zeit, Ethiopia.

15. Kasier MN (1987) Report on tick taxonomy and biology AG: DP/ETH/83/023 Consultants Report FAO. p: 92.
16. De castro JJ (1994) Sustainable tick and tick-born disease control in livestock improvement in developing countries. Vet Parasitol 71: 77-97.

17. Urquhart GM, Armour A, Duncan JL, Dunn AM, Jennings FW (1996) Veterinary Parasitlogy. 2nd edn. Black Well Sciences Ltd., p: 231.

18. Soulsby EJ (1982) Helminthes, Arthropods and Protozoa of domestic animals 7th edn. Lea and Febiger, Philadelphia, USA, pp: 40-52.

19. Mekonnen S (1995) Ticks, Tick-borne diseases and control strategies in Ethiopia. In: Tick borne pathogens at the host vector interface.

20. Mekonen S (1991) Tick and tick-borne disease control in Ethiopia. In Proceeding of Joint OAU, FAO and ILRDA work shop held in Liongwe, Alwi, pp: 19-20.

21. Pawlos W, Derese D (2013) Study on prevalence and identification of ticks in Humbo District, Southern Nations, Nationalities and People's Region (SNNPR) Ethiopia. J Vet Med Anim Health 5: 73-80.

22. Aiello SE (1998) Ticks. In: The Merck Veterinary Manual. 8th edn. Merck and Co. Inc., Whitehouse Station. USA, pp: 670-686

23. Sinshaw A (2000) Distribution of ticks and tick-borne disease at Metekel ranch Ethiopia. Ethiop Vet J 4: 40 -59.

24. Behailu B (2004) A survey of ticks and tick-borne blood protista in cattle at Asselas, Arsi zone. DVM Thesis FVM, AAU. 